\title{
Discrepancies in the Ideal Perceptions and the Current Experiences of Special Education Teachers
}

\author{
Amanda Andrews ${ }^{1}$, Jennifer L. Brown ${ }^{1}$ \\ ${ }^{1}$ College of Education and Health Professions, Columbus State University, Columbus, Georgia \\ Correspondence: Jennifer L. Brown, Department of Teacher Education, Columbus State University, 4225 University \\ Avenue, Columbus, Georgia
}

Received: July 29, 2015 Accepted: August 11, $2015 \quad$ Online Published: August 27, 2015

doi:10.11114/jets.v3i6.984 URL: http://dx.doi.org/10.11114/jets.v3i6.984

\begin{abstract}
The field of special education continues to have lower teacher retention rates compared to general education. As a result, concerns over the quality of special education teachers' professional experiences have risen. Both general and special education teachers have their ideal views of the profession, including ample classroom facilities, available resources, and supportive administration; however, many factors can cause teachers to have less than ideal experiences in the field. The purpose of this study was to examine special education teachers' ideal perception of teaching compared to their current experiences. The researchers conducted a causal comparative research study using the Perceptions of Success Inventory for Beginning Teachers (Corbell, Osborne, \& Reiman, 2010; Corbell, Reiman, \& Nietfeld, 2008). The study included a sample of 14 participants employed as special education teachers in one school system located in the southeastern United States. A series of paired sample $t$-test analyses were conducted. The results revealed special education teachers' current experiences were rated significantly lower than their ideal perceptions in 7 out of 8 scales (i.e., colleagues, administration, classroom, success, resources, workload, and parents). This research could provide administrators with insight into what special education teachers view as essential, or ideal, for effective teaching. Then, administrators can better determine how teachers' current experiences are or are not meeting the teachers' expectations.
\end{abstract}

Keywords: experiences, special education, teacher perceptions

\section{Introduction}

\subsection{The Problem}

Many special education teachers enter the field inspired to help students with special learning needs (Crutchfield, 1997); however, working with the special education population has its own challenges. Special education teachers have to be able to work with students with a range of disabilities, from mild to severe, in addition to increasing caseloads (Emery \& Vandenberg, 2010). These challenges cause special education teachers to have less than ideal experiences in the classroom. Zabel, Boomer, and King (1984) found continued dissatisfaction and unpleasant feelings when teachers' experiences did not match their expectations. When teachers' experiences are less than their ideal expectations, they begin to experience burnout.

According to Maslach (1982), burnout is defined as emotional exhaustion, depersonalization, and feeling unaccomplished. Specifically, compassion fatigue is a type of burnout that occurs in individuals working in a profession that seeks to help other individuals. Compassion fatigue can cause special education teachers to devalue their work with students and lose their motivation to teach. Professional stress contributes to an educator's feelings of compassion fatigue. Professional stress occurs in a variety of ways among special education teachers including difficulty meeting standards while also meeting student needs, excess paperwork, low salaries, lack of recognition, unpleasant interpersonal interactions, loss of control, lack of supplies, and inadequate opportunity for professional interactions and growth (Wisniewski \& Gargiulo, 1997). When these stressful issues are not recognized and resolved, special education teachers choose to leave the field. The average special education teachers will work in the classroom a total of 6 years (Singer, 1993). The attrition rates for special education teachers have remained higher than attrition rates of general education teachers for decades (Emery \& Vandenberg, 2010). High turnover rates have caused special education teaching positions to be filled by teachers who are not fully certified in the area (Crutchfield, 1997). As a result, students in special education and their parents may also have less than ideal experiences in the classroom. 


\subsection{Theoretical Orientation}

In Social Cognitive Theory, psychologist Albert Bandura theorized that behavior is influenced by the combination of personal (e.g., thoughts and preferences), behavioral, and environmental determinants interacting bi-directionally (Wood \& Bandura, 1989). Bandura identified this interaction as a triadic reciprocal relationship. Prior to Bandura, behavior had been theorized as unidirectional, influenced by either environmental factors or internal factors. Aligning with Bandura, the researchers of the current study hypothesized that special education teachers' work experiences were influenced by their environment, by their cognitions (e.g., perceptions), and by their behaviors, thus creating a triadic reciprocal relationship. Special education teachers' perceptions of their current and ideal experiences in teaching affect their behavior, as well as the school environment (i.e., colleagues). The school environment also influences special education teachers' perceptions and behavior. Special education teachers' behavior influences their perceptions as well as the school environment.

Bandura also theorized that an individual's beliefs are highly influenced by self-efficacy (Wood \& Bandura, 1989). Special education teachers' belief in their ability to accomplish desired outcomes can affect their perception of their current and ideal experiences. Efficacy expectation is the belief in one's self to successfully perform the required behavior in order to produce the expected outcomes (Bandura, 1977). Special education teachers can become burned out when their desired or expected outcomes are perceived as too challenging to accomplish. Bandura recognized that, when expectations are not recognized or achieved, performance and commitment decrease (Bandura, 1977).

\subsection{Review of the Literature}

In the Teacher Stress and Burnout model, Zabel et al. (1984) proposed that burnout occurs from incongruence between a teacher's expectations and the school experience. The model concludes that each component (i.e., teachers' expectations, school experiences, feelings, and behavior, as well as others' reactions) have an interactive effect on each other. Springer, Morganfield, and Diffily (2007) surveyed teachers and students on their preferred and actual experiences in the classroom. The researchers used the Texas state educator standards to create the survey questions. The results revealed higher means for teachers' preferred experiences compared to the means for teachers' actual experiences for all nine competencies surveyed (i.e., instructional goals, instructional strategies, classroom atmosphere, classroom management, communication, student engagement, assessment, diversity, and technology). The highest mean difference for teachers' preferred and actual experiences was the diversity standard. The diversity competency involved the teacher having an understanding of student diversity and the ability to create plans that consider differences among students. The lowest mean difference for teachers' preferred and actual experiences was the instructional goals standard. The instructional goals competency held the teachers accountable for creating effective and understandable lessons as well as assessments based on learning goals and objectives. The researchers concluded that teachers believe they have too many responsibilities and, therefore, are unable to create their ideal standards in the classroom. According to Zabel et al. (1984), teachers who are unable to find some level of congruence between their expectations and experiences will continue to experience stress and become burnout; however, if teachers are able to modify their expectations to be more congruent with reality or create a reality that is closer to their expectations, they will cope better with stress and are less likely to experience burnout.

The importance of teacher's perceptions and experiences cannot be under estimated. A research study surveyed graduates beliefs about education just before entering their first year of teaching (Taylor, Leitman, \& Barnett, 1992). A second survey measured the new teachers' experiences immediately following their first year. The survey findings revealed that participants' experiences changed their perceptions of education. Before completing their first year of teaching, $93 \%$ of participants strongly agreed that all children can learn, while only $88 \%$ believed the same after their teaching experience. Additionally, $83 \%$ of participating teachers strongly agreed they could make a difference in the lives of their students prior to any experience as a pre-service teacher, while only $68 \%$ strongly agreed after one year of teaching in the classroom. Regarding principal support, $98 \%$ of the participants believed prior to their first year experience that the principal would create a positive environment for learning. By the end of the participants' first year, $87 \%$ reported that their principal had successfully created a positive environment. After their first year teaching, nearly half of the participants (43\%) continued to believe that teachers are not respected in society; a slight increase from $40 \%$ of participants who held this belief prior to their first year. These findings depict how a teacher's experiences can significantly affect his or her perceptions. A study conducted in the Bahamas surveyed primary school teachers' perceptions of inclusive education (Hunter-Johnson, Newton, \& Cambridge-Johnson, 2014). The results revealed that participants' perceptions are primarily negative, $60 \%$; however, $30 \%$ of the participants had mixed feelings about inclusive education. Only one teacher strongly supported the idea of inclusion classrooms. Participants did not have experience teaching in inclusion classrooms, but they noted various factors that contributed to their perceptions of inclusive education (i.e., teacher training, resources, support, infrastructure, and understating of inclusive education). The researchers concluded that teachers' perceptions are likely to influence the implementation and success of 
experiences, such as teaching in an inclusive setting. In other words, teachers' perceptions can greatly impact their experiences before the experiences begin.

There are several research studies on the perceptions and experiences of general education teachers; however, there is little literature comparing special education teachers' ideal views of teaching to their current teaching experiences. Additional research on this topic would help to provide insight on the perceptions of current special education teachers' experiences as well as what these teachers identify as essential to the special education teaching experience. The purpose of this study was to examine how special education teachers' ideal perceptions compare to their current experiences with parent contact, administrative and colleague support, classroom management, student success, resources, workload, and assessment.

\section{Method}

\subsection{Participants}

The sample consisted of 14 participants from one school district within southeastern U.S. Of these participants, 11 completed the survey in full. Nine of the participants were female, and two were male. All participants were at least 36 years of age or older, and all participants had taught for more than 3 years at the time of the survey. Three participants (27\%) held a T-5 certification license (i.e., master's degree was the highest degree held), five held a T-6 (i.e., educational specialist's degree was the highest degree held), one held a PBT-6 (i.e., provisional license), and two specified other types of licensure. Regarding instructional space, two participants shared a classroom with other teachers throughout the day while six participants did not share a classroom. Three participants moved classrooms throughout the day. Four participants indicated their involvement in graduate school, four participants indicated involvement in a religious affiliation, and three indicated their participation in a service organization. When asked about future career plans, only $1(9.1 \%)$ participant indicated he or she was preparing to leave teaching in the future; however, $4(36.4 \%)$ participants indicated they had intentions to continue teaching in the 2014-2015 academic year though they had considered leaving. One participant was making plans to continue teaching in the state but change school districts. Nearly half $(45.5 \%, n=5)$ of participants indicated no intention to leave teaching.

\subsection{Measure}

The Perceptions of Success Inventory for Beginning Teachers (PSI-BT) (Corbell, Osborne, \& Reiman, 2010; Corbell, Reiman, \& Nietfeld, 2008) was designed to measure beginning teacher perceptions of success. The survey measures success based on the factors of support (i.e., mentor support, colleague support, and administrative support), classroom management, student success, instructional resources, workload/assignment, parental contact, satisfaction, and commitment. The PSI-BT measure contained eight scales for the purposes of this study: colleague support, administrative support, classroom management, student success, instructional resources, workload, parent contact, and assessment. The Colleague Support Scale assessed whether teachers have opportunities to communicate with colleagues through planning times with other teachers in the same subject or grade level areas, as well as time to visit or observe other, more experienced, teachers. The Administrative Support Scale assessed the teachers' perception of administrative contact, help with orientation to the school and staff, feedback on discipline, encouragement, and effective instructional leadership. The Classroom Management Scale assessed the teachers' perceptions of their classroom management through their feedback on the clarity and consistency of classroom routines and procedures, effectiveness of discipline, and their feelings of being in control. The Student Success Scale assessed the teachers' confidence in differentiating instruction, motivating students, as well as their ability to teach students with disabilities, students from diverse backgrounds, and students with limited English proficiency. Items included in the Instructional Resources Scale assessed the teachers' access to state-aligned curriculum, whether professional development was valuable, the teacher's confidence in using available technology, as well as their confidence in grading student work and reporting student assessments. The Workload Scale assessed teacher perceptions on the amount of preparations appropriate for a beginning teacher, whether the teachers' schedule included at least one planning period without interruptions, whether the teachers' overall workload was reasonable, whether the teachers were able to choose to add extra duties, and whether the teachers were content with state and national testing policies. The Parent/Caregiver Contact Scale assessed whether parents were supportive of their child's academic progress, the teachers' confidence in communicating with parents, if they received guidance from colleagues or administrators concerning parent communications, and the teachers' perceptions on the importance of communicating with parents (Reiman \& Corbell, 2007). The Assessment Scale assessed the teachers' perceptions of formative and summative assessments in addition to high stakes testing. Participants were asked to rate each item based on their level of agreement for their current experience and ideal perception using a 6-point Likert-type scale, with 6 representing Strongly Agree. Additional demographic information was collected including gender and age range.

Corbell et al. (2010) conducted a study with 439 beginning teachers in their first 3 years of teaching to determine 
reliability and validity of the PSI-BT using confirmatory factor analysis. The alpha coefficient was found for colleague support $(\alpha=.60)$, administration support $(\alpha=.91)$, classroom management $(\alpha=.91)$, student success $(\alpha=.88)$, instructional resources $(\alpha=.71)$, workload $(\alpha=.68)$, and parental contacts $(\alpha=.76)$. The measure was found to have construct validity and could be used to predict retention of special education teachers. The Assessment Scale was developed after the initial validation process (M. Smith, personal communication, February 6, 2015). A Cronbach's alpha coefficient of .50 or greater was established as the criterion for reliability for this study (Thorndike, 1951). Reliability analyses were conducted with the current study's data. The alpha coefficients ranged from .53 to .93 for the current experiences, and the alpha coefficients ranged from .51 to .91 from the ideal experiences. Table 1 displays the alpha coefficients for each scale within the current study. Based on these alpha coefficients, the measure was found to be internally consistent.

Table 1. Alpha Coefficients for each Scale by Group

\begin{tabular}{|c|c|c|}
\hline \multirow[b]{2}{*}{ Scale } & \multicolumn{2}{|c|}{ Alpha Coefficient } \\
\hline & Current & Ideal \\
\hline Colleague Support & .75 & .78 \\
\hline Administrative Support & .89 & .85 \\
\hline Classroom Management & .92 & .85 \\
\hline Student Success & .85 & .82 \\
\hline Instructional Resources & .93 & .91 \\
\hline Workload & .53 & .51 \\
\hline Assessment & .82 & .72 \\
\hline Parental Contact & .82 & .82 \\
\hline
\end{tabular}

2.3 Data Collection

The researchers received IRB approval from their university and the targeted school district. Then, they collected email addresses from the school system's website to recruit participants. Three emails were sent to invite the school district's special education teachers to participate in the study. The survey was created by SUCCEED (School-University Collaboration \& Commitment to Excellence in Educators' Development), part of the Department of Curriculum and Instruction at North Carolina State University, using Qualtrics, a web-based survey software. An anonymous link was included in the invitation to participate emails, which the participants could select or copy and paste the link into their internet browser. At the beginning of the survey, participants were given the opportunity to consent to the use of their responses for research. The participants took between 30 to 45 minutes to complete the survey. Once the data collection phase was completed, SUCCEED sent the researchers the raw data within an Excel spreadsheet.

\section{Results}

The researchers conducted a quasi-experimental research study using data collected from the PSI-BT (Corbell et al., 2010; Corbell et al., 2008). Data from the Excel spreadsheet was imported into SPSS. A series of paired sample $t$-test analyses were conducted with each of the eight scales.

\subsection{Colleague Support}

A paired-samples $t$-test was conducted to compare participants' current experiences and ideal perceptions of colleague support. There was a significant difference in the scores for ideal perceptions $(M=5.70, S D=0.37)$ and current experiences $(M=3.77, S D=1.25) ; t(13)=5.12, p=.000$. These results suggest that participants' perceptions of their current experiences with colleague support were significantly less than their ideal expectations. The researchers concluded that multiple factors contribute to this imbalance. One factor could be that special education teachers may feel isolated from colleagues due to a lack of time available to meet with other special education teachers who can provide insight and encouragement.

\subsection{Administrative Support}

A paired-samples $t$-test was conducted to compare participants' current experiences and ideal perceptions of administrative support. There was a significant difference in the scores for ideal perceptions $(M=5.36, S D=0.64)$ and current experiences $(M=4.41, S D=1.47) ; t(13)=2.17, p=.049$. These results suggest that participants' perceptions of their current experiences with administrative support were significantly less than their ideal expectations. Many special education teachers may feel they have too little contact or encouragement from their school leadership.

\subsection{Classroom Management}

A paired-samples $t$-test was conducted to compare participants' current experiences and ideal perceptions of classroom management. There was a significant difference in the scores for ideal perceptions $(M=5.62, S D=0.40)$ and current 
experiences $(M=5.51, S D=0.45) ; t(13)=.02, p=.015$. These results suggest that participants' perceptions of their current experiences with classroom management were slightly less than their ideal expectations. The researchers hypothesize that participants of this study have veteran experience in the role of classroom manger; therefore, they feel successful in achieving what they perceive as ideal. Applied generally, teachers perceive classroom management as an area they can control without much outside support; therefore, teachers might feel they can successfully work toward classroom management that meets their ideal expectations.

\subsection{Student Success}

A paired-samples $t$-test was conducted to compare participants' current experiences and ideal perceptions of student success. There was a significant difference in the scores for ideal perceptions $(M=5.60, S D=0.38)$ and current experiences $(M=5.22, S D=0.59) ; t(12)=3.70, p=.003$. These results suggest that participants' perceptions of their current experiences with student success were slightly less than their ideal expectations. The researchers concluded that student success could be perceived by teachers as internally controlled and therefore more easily achievable.

\subsection{Instructional Resources}

A paired-samples $t$-test was conducted to compare participants' current experiences and ideal perceptions of instructional resources. There was a significant difference in the scores for ideal perceptions $(M=5.69, S D=0.40)$ and current experiences $(M=4.00, S D=1.46) ; t(12)=4.02, p=.002$. These results suggest that participants' current experiences with instructional resources were significantly less than their ideal expectations. This outcome may be due to teachers having to seek out their own curriculum and resources or go without. Special education teachers may also feel they need more professional development covering relevant topics.

\subsection{Workload}

A paired-samples $t$-test was conducted to compare participants' current experiences and ideal perceptions of workload. There was a significant difference in the scores for ideal perceptions $(M=5.42, S D=0.50)$ and current experiences $(M=$ $3.40, S D=1.05) ; t(11)=5.79, p=.000$. These results suggest that participants' perceptions of their current experiences with workload were significantly less than their ideal expectations. Special education teachers might feel they have too much paperwork and believe they cannot successfully keep up with the continually changing requirements.

\subsection{Parental Contact}

A paired-samples $t$-test was conducted to compare participants' current experiences and ideal perceptions of parent contact. There was a significant difference in the scores for ideal perceptions $(M=5.61, S D=0.49)$ and current experiences $(M=4.55, S D=1.28) ; t(10)=2.52, p=.030$. These results suggest that participants' perceptions of their current experiences with parent contact were significantly less than their ideal expectations. Special education teachers, novice or veteran, may not feel comfortable speaking with parents. Additionally, these teachers may feel discouraged when they do not see parental involvement in the students' education.

\subsection{Assessment}

A paired-samples $t$-test was conducted to compare participants' current experiences and ideal perceptions of assessment. There was not a significant difference in the scores for ideal perceptions $(M=4.652, S D=0.54)$ and current experiences $(M=4.654, S D=0.64) ; t(10)=-.026, p=.980$. These results suggest that participants' perceptions of their current experiences with assessment were similar to their ideal expectations. The researchers hypothesize that special education teachers have lower expectations of ideal assessment; assessment may be viewed as something that simply must be done in a data driven culture.

\section{Discussion}

The results revealed participants' current experiences were rated significantly lower than their ideal perceptions in 7 out of 8 scales (i.e., colleagues, administration, classroom, success, resources, workload, and parents). The only scale which had a higher rating for current experiences compared to ideal perceptions was assessment. The greatest mean rating difference was found between current experiences with workload and ideal perceptions of workload. The least difference in mean ratings was between participants' current experiences and ideal perceptions of classroom management. Interestingly, the results also indicated that participants felt they experienced student success in their current experiences at only a slightly lower rate than their ideal perceptions of student success. These findings could suggest that special education teachers are more satisfied in areas they have greater perceived control (e.g., classroom) compared to externally assigned pressures (e.g., workload). These findings could suggest congruence with Bandura's reciprocal determinism; that is, when a special education teacher believes he or she has established a classroom conducive to student success then the educator's behaviors and environment are positively influenced to maintain success.

This research could provide administrators with insight into what special education teachers view as essential, or ideal, for 
effective teaching. Then, administrators can better determine how teachers' current experiences are or are not meeting the teachers' expectations. As a result, administrators could gain a better understanding of what is needed to keep well qualified teachers on staff.

Some limitations existed within this study. First, the research study was conducted in only one school district. Comparing more special education teachers' experiences in multiple school districts would provide greater insight. The sample size was also small and consisted mostly of female participants. Future research could utilize larger more diverse sample sizes. Furthermore, the PSI-BT (Corbell et al., 2010; Corbell et al., 2008) was designed for surveying novice special education teachers. The researchers had intended to gather data on beginning special education teachers' experiences; however, all participating special education teachers had 3 or more years of teaching experience. Additional research of experienced special education teachers can provide insight on the reasons special education teachers stay in the field and help determine the generalization of the current study results.

\section{References}

Bandura, A. (1977). Self-efficacy: Toward a unifying theory of behavioral change. Psychological Review, 84, 191-215. http://dx.doi.org/10.1037/0033-295X.84.2.191

Corbell, K. A., Osborne, J., \& Reiman, A. J. (2010). Supporting and retaining beginning teachers: A validity study of the perceptions of success inventory for beginning teachers. Educational Research and Evaluation, 16(1), 75-96. http://dx.doi.org/10.1080/13803611003722325

Corbell, K. A., Reiman, A. J., \& Nietfeld, J. L. (2008). The perceptions of success inventory for beginning teachers: Measuring its psychometric properties. Teaching and Teacher Education, 24(6), 1551-1563. http://dx.doi.org/10.1080/13803611003722325

Crutchfield, M. (1997). Who's teaching our children with disabilities? News Digest, 27, 2-25.

Emery, D. W., \& Vadenberg, B. (2010). Special education teacher burnout and ACT. International Journal of Special Education, 25(3), 119-131.

Hunter-Johnson, Y., Newton, N. G. L., \& Cambridge-Johnson, J. (2014). What does teachers' perception have to do with inclusive education: A Bahamian context. International Journal of Special Education, 29(1), 143-157.

Maslach, C. (1982). Burnout: The cost of caring. Englewood Cliffs, NJ: Prentice-Hall.

Reiman, A., \& Corbell, K. (2007). A summary report for collaborative effort to support new professionals. Raleigh, NC: North Carolina State University.

Singer, J. D. (1993). Once is not enough: Former special educators who return to teaching. Cambridge, MA: Harvard University.

Springer, K., Morganfield, B., \& Diffily, D. (2007). Actual versus preferred classroom experience among secondary teachers and their students. American Secondary Education, 35(2), 17-35.

Taylor, H., Leitman, R., \& Barnett, S. (1992). The American teacher, 1992. The second year: New teachers' expectations and ideals. A survey of new teachers who completed their second year of teaching in public schools in 1992. The metropolitan life survey. New York: Harris (Louis) and Associates, Inc. (ED354226)

Thorndike, R. L. (1951). Reliability. In E. F. Linquist (Ed.), Educational measurement. Washington, DC: American Council on Education.

Wisniewski, L., \& Gargiulo, R. M. (1997). Occupational stress and burnout among special educators: A review of the literature. The Journal of Special Education, 31(3), 325-346. http://dx.doi.org/10.1177/002246699703100303

Wood, R., \& Bandura, A. (1989). Social cognitive theory of organizational management. Academy of Management Review, 14(3), 361-384. http://dx.doi.org/10.5465/AMR.1989.4279067

Zabel, R. H., Boomer, L. W., \& King, T. R. (1984). A model of stress and burnout among teachers of behaviorally disordered students. Behavioral Disorders, 9, 215-221. 